\title{
BMJ Open Quality Effects of working environments with minimum night lighting on night-shift nurses' fatigue and sleep, and patient safety
}

\author{
Hokuto Hoshi, ${ }^{1,2}$ Hajime Iwasa, ${ }^{2}$ Aya Goto, ${ }^{3}$ Seiji Yasumura ${ }^{2}$
}

To cite: Hoshi $\mathrm{H}$, Iwasa $\mathrm{H}$, Goto A, et al. Effects of working environments with minimum night lighting on night-shift nurses' fatigue and sleep, and patient safety. BMJ Open Quality 2022;11:e001638. doi:10.1136/ bmjoq-2021-001638

Received 11 August 2021 Accepted 16 December 2021

A) Check for updates

(C) Author(s) (or their employer(s)) 2022. Re-use permitted under CC BY-NC. No commercial re-use. See rights and permissions. Published by BMJ.

${ }^{1}$ Koeki Zaidan Hojin Hoshi Sogo Byoin, Koriyama, Fukushima, Japan

${ }^{2}$ Department of Public Health, Fukushima Medical University School of Medicine, Fukushima, Japan

${ }^{3}$ Center for Integrated Science and Humanities, Fukushima Medical University, Fukushima, Japan

Correspondence to Dr Hokuto Hoshi; hoshipital@gmail.com

\section{ABSTRACT}

Objective Nurses working rotating shifts often suffer from insomnia or similar disorders because exposure to room lighting at night inhibits melatonin secretion, resulting in a disturbed circadian rhythm. This study investigated whether dark room lighting would be preferable to brighter rooms in terms of (1) fatigue and sleepiness while working, (2) quality of sleep and (3) non-interference with work performance among nurses.

Methods This study used a non-randomised open-label trial between night shifts using dark (110 Ix) and bright (410 Ix) room lighting on the desk surface. A total of 20 nurses were enrolled in the trial from November 2015 to February 2016 at a hospital in Japan. All participants worked first with dark room lighting and then with bright room lighting. The participants completed a selfadministered questionnaire at enrolment, which was collected this at the end of the intervention.

Results Fatigue and sleepiness were significantly higher in dark room lighting than in bright room conditions $(p<0.05)$. There were no significant differences in sleep quality between the dark and well-lit conditions. We detected no significant differences in the number of reported incidents or accidents comparing the two types of environments.

Conclusion Dark room lighting did not ameliorate fatigue and sleepiness during night shifts. Additionally, there was no evidence of improvement in sleep quality among nurses. These findings are important, however, in terms of managing hospital risk.

\section{BACKGROUND}

Currently, hospital nurses in Japan work in two shifts: in the daytime $(08: 45$ to $17: 15$ hours at the study hospital; 8 hours $30 \mathrm{~min}$ with a break), and at night (16:45 to 09:15 am the next day; 16 hours 30 min with a break). Night-shift nurses take a break or nap for 2 hours during long working hours. Some hospitals employ nurses who work night shifts only, but nurses generally work both day and night shifts.

In humans, a lighting environment of $>300$ lx inhibits melatonin secretion even with a short exposure time of $1-2$ hours. ${ }^{1-3}$ With an exposure time of more than a certain number of hours, a lighting environment of $120 \mathrm{~lx}$ or higher also inhibits melatonin secretion. ${ }^{4}$ This inhibition has a harmful effect on the circadian rhythm of night-shift nurses working in the usual lighting environment, disrupting naps or sleep rhythms after the night shift. ${ }^{5}$ Reportedly, consecutive shift changes between night and day disrupt circadian rhythms and lead to problems such as insomnia, which is one of the reasons why nurses leave their jobs. ${ }^{6-8}$ Additionally, lifestyle factors (including exercise, sleep patterns, timing of meals and alcohol consumption) affect the circadian rhythms of nurses. It is important for hospital managers to help reduce nurse turnover because of work environment issues.

Humans temporarily stop feeling sleepy in an extremely well-lit environment of approximately 5000 lx. ${ }^{8}$ Some reports state that short exposure to extremely bright light changes sleepiness in night-shift workers. ${ }^{9-11}$ Temporary periods of wakefulness during the night may disrupt circadian rhythms. Since there is little scientific evidence related to how minimum lighting at night influences nurses' health and work, we aimed to find an ideal solution to minimise disruption of nurses' circadian rhythm and maximise hospital safety management.

\section{Study aims}

The authors hypothesised that disruption of shift workers' circadian rhythms could be prevented if night lighting was kept below 120 lx (hereafter, 'a dark environment'), a level that does not inhibit melatonin even with long-term exposure. ${ }^{1-4}$ It should be noted that $120 \mathrm{~lx}$ complies with the Japanese regulations of the Industrial Safety and Health Act, which set $70 \mathrm{~lx}$ as the minimum requirement for work involving strenuous activities, and 100 lx for a hospital room.

The objectives of this study were to investigate whether dark environments improve 
nurses' (1) fatigue and sleepiness while working, (2) quality of sleep and (3) reduce interference with work performance (malpractice/incidents/accidents).

\section{METHODS}

In this quasi-experimental study, participants received a control treatment, followed by a washout period, and then received the intervention. The study was conducted at a 430-bed general hospital that mainly provides acute care, located in a Japanese city with a population of approximately 330000. The hospital was originally designed to use minimal lighting. Some nurses in the hospital complained that, when working a night shift, they had to go back and forth between dark patient rooms and much brighter work stations. All wards, therefore, except for the intensive care unit and emergency department were constructed to have 'dark conditions' with only $110 \mathrm{~lx}$ in the work spaces.

Dark conditions were defined as approximately 110 lx (colour temperature: 3500K, Color Rendering Index: Ra85) on the desk at the staff station, while well-lit conditions were defined as approximately $410 \mathrm{~lx}$ (colour temperature: 3500K, CRI: Ra85) on the desk, with additional ceiling lights used to create a bright environment during the second half of the study period. During daytime, well-lit conditions of approximately 630 lx were maintained, while the dark condition was maintained at $600 \mathrm{~lx}$; these were determined to be equivalent to each other.

Nurses who worked rotating shifts in a general ward and those who regularly had a night shift about five times per month with more frequent day shifts participated in the study. We calculated sample size by assuming a tolerance of $18 \%$, CI of $95 \%$ and a response rate of $60 \%$, finally arriving at a sample size of 28 participants. Thirty participants potentially would provide statistically significant differences in main outcome indicators between the two conditions. The study measured the impact of the night shift with or without dark lighting through a questionnaire completed on the last day of a run of consecutive day shifts and on the first day shift after a night shift. Over the 4-month study period, the participants underwent two phases depending on daylight exposure time between two conditions. The dark condition phase was conducted from 1 November to 31 December 2015, during a period when the ward was routinely used under this condition. The well-lit phase was conducted from 1 January to 29 February 2016. This time period was intentionally selected because of its minimal daylight.

\section{Study period}

Questionnaires were collected from the participants during the latter half of the second month for each condition. The latter half of the second month for dark condition ran from 17 to 30 November 2015 and that for the well-lit condition was the period from 16 to 29 February 2016.
Reports of medical treatment problems related to work performance were analysed for the entire month of exposure. Reports for the dark conditions were recorded for the period from 1 to 30 November 2015 and those for the well-lit conditions were taken from the period from 1 to 29 February 2016.

\section{Questionnaires}

A self-administered questionnaire was given to the participants at enrolment and collected at the end of the intervention.

The questions about fatigue and sleepiness were taken from 'Subjective Symptoms (2002)', developed by the Industrial Fatigue Research Committee of the Japan Association of Industrial Health. ${ }^{12}$ This assessment is performed before and after work for comparison, with higher scores indicating stronger fatigue or sleepiness.

The questions about sleep quality assessed at time of waking were taken from the 'Oguri-Shirakawa-Azumi Sleep Inventory MA Version' ${ }^{, 13}$ which is a self-assessment of sleep quality. The questions about 'sleep quality' covered five factors: sleepiness on waking, sleep induction and maintenance, dreaming, recovery from fatigue and sleep duration. These five factors comprised 16 questions. Higher scores indicate better sleep quality. The questionnaire could be completed at any time during and after the shift. For the night shift, a question about 'feeling sleepy on waking after a nap' was added.

Questions about malpractice/incidents/accidents were quantitatively compared by severity level based on all the reports compiled at this hospital. From these reports, we examined whether there was any mention of the effect of lighting environment, such as light intensity or visibility. The severity was classified into eight levels that were used ranging from a near-miss (level 0) to death (level 5 ). Levels 3 and 4 were further divided into 'a' and 'b'; 'b' was more severe than ' $a$ '. Level $3 b$ or higher was defined as an accident. ${ }^{14}$ Level $3 \mathrm{~b}$ was defined as 'a temporary injury of severe degree, for which extensive treatment was needed (severe change in vital signs, ventilator, surgery, extension of hospital stays, hospital admission as an outpatient, bone fracture, etc)'. Thus, levels above 3a included all serious issues. Data collection and analyses were performed using this classification. The analysis used a final severity level decided by an independent clinical safety committee of the hospital and was not based on the report.

\section{Analysis method}

A t-test was used to evaluate the difference in the average values. Fisher's exact test was used to determine differences in numbers by group. Statistical significance was set at $p<0.05$. We compared results between the two conditions, and the results before and after night shifts under the same conditions. An analysis of incident and accident reports was also performed. It examined the results in a $2 \times 2$ table divided by condition and severity for both day shifts and night shifts. Furthermore, related to the total number of reports and comparisons between conditions, 
the total number of day and night shifts in the surveyed ward were also compared with those in other wards simultaneously.

\section{Patient and public involvement}

Participants of this study were nurses working at a general hospital. Although patients at the hospital were not involved, participants were fully informed of significance of this study and possible benefits derived from this study results for them.

\section{RESULTS}

\section{Participant demographics}

The ward had 30 beds, and there were 30 rotating shift nurses. Of the 30 nurses who had the study explained to them in the ward, 20 were enrolled in the study after providing informed consent. One participant withdrew from the study after being transferred to another ward. Another participant who was transferred from another ward in the hospital joined in the middle of the study period. Of the 20 participants, 19 completed questionnaires for the dark exposure phase. The data for two participants were excluded as one used sleeping pills and the other failed to respond to some questions. Data of the remaining 17 subjects were analysed. For the well-lit condition, data from 10 participants were used for the analysis. Nine did not respond to the questionnaire for the well-lit condition. There were no differences in age, work experience or corrected eyesight (table 1).

\begin{tabular}{|c|c|c|c|}
\hline & & $\begin{array}{l}\text { Dark } \\
\text { condition } \\
\text { ( } \mathrm{n}=17)\end{array}$ & $\begin{array}{l}\text { Well-lit } \\
\text { condition } \\
(n=10)\end{array}$ \\
\hline \multirow[t]{2}{*}{ Sex } & Male & 0 & 1 \\
\hline & Female & 17 & 9 \\
\hline Age & Mean \pm SD & $34.6 \pm 13.2$ & $36.0 \pm 13.1$ \\
\hline $\begin{array}{l}\text { Mean duration } \\
\text { of work }\end{array}$ & Mean \pm SD & $12.4 \pm 13.6$ & $13.6 \pm 13.4$ \\
\hline \multirow[t]{2}{*}{ Sleep disorder } & No & 11 & 7 \\
\hline & No answer & 6 & 3 \\
\hline \multirow[t]{2}{*}{ Sleeping drug } & No & 12 & 7 \\
\hline & No answer & 5 & 3 \\
\hline \multirow[t]{5}{*}{ Past illness } & Allergy & 1 & 0 \\
\hline & Asthma & 1 & 1 \\
\hline & $\begin{array}{l}\text { Myoma of the } \\
\text { uterus }\end{array}$ & 1 & 0 \\
\hline & Fatty liver & 0 & 1 \\
\hline & Slipped disk & 1 & 0 \\
\hline \multirow{2}{*}{$\begin{array}{l}\text { Corrected } \\
\text { eyesight }\end{array}$} & Left & $0.94 \pm 0.27$ & $0.76 \pm 0.43$ \\
\hline & Right & $0.92 \pm 0.32$ & $0.81 \pm 0.63$ \\
\hline
\end{tabular}

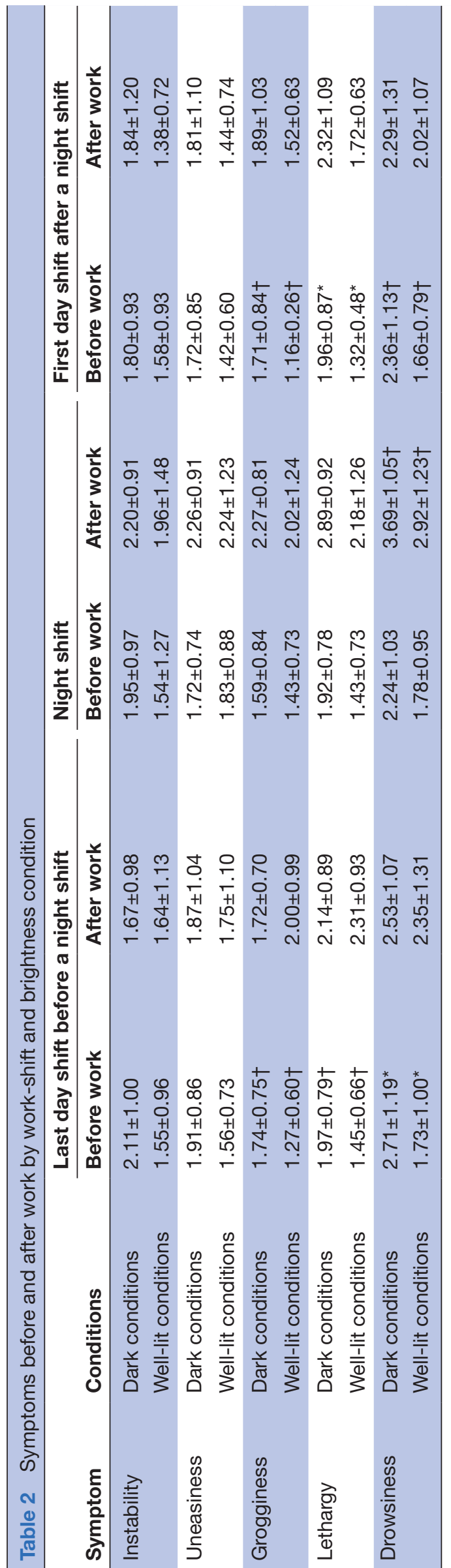


Table 3 Self-assessment of sleep quality by work-shift and conditions

\begin{tabular}{|c|c|c|c|c|c|c|}
\hline \multirow[b]{2}{*}{ Factors } & \multirow[b]{2}{*}{ Elements } & \multirow[b]{2}{*}{ Conditions } & \multirow{2}{*}{$\begin{array}{l}\begin{array}{l}\text { Last day shift } \\
\text { before a night } \\
\text { shift }\end{array} \\
\text { On waking } \\
\text { (mean } \pm \text { SD) }\end{array}$} & \multicolumn{2}{|l|}{ Night shift } & \multirow{2}{*}{$\begin{array}{l}\text { First day shift } \\
\text { after a night } \\
\text { shift } \\
\text { On waking } \\
\text { (mean } \pm \text { SD) }\end{array}$} \\
\hline & & & & $\begin{array}{l}\text { On waking } \\
\text { (mean } \pm S D)\end{array}$ & $\begin{array}{l}\text { After a nap } \\
\text { (mean } \pm S D)\end{array}$ & \\
\hline \multirow[t]{2}{*}{ I } & \multirow{2}{*}{$\begin{array}{l}\text { Sleepiness on } \\
\text { waking }\end{array}$} & Dark conditions & $38.09 \pm 12.84$ & $40.93 \pm 8.75$ & $32.82 \pm 9.44$ & $38.67 \pm 10.40$ \\
\hline & & $\begin{array}{l}\text { Well-lit } \\
\text { conditions }\end{array}$ & $42.48 \pm 11.92$ & $41.83 \pm 13.10$ & $37.47 \pm 14.06$ & $40.38 \pm 12.43$ \\
\hline \multirow[t]{2}{*}{ II } & \multirow{2}{*}{$\begin{array}{l}\text { Sleep induction } \\
\text { and maintenance }\end{array}$} & Dark conditions & $46.33 \pm 7.84^{\star}$ & $46.11 \pm 7.41$ & $37.95 \pm 9.45$ & $46.55 \pm 9.86$ \\
\hline & & $\begin{array}{l}\text { Well-lit } \\
\text { conditions }\end{array}$ & $52.13 \pm 9.94^{*}$ & $46.56 \pm 10.85$ & $31.15 \pm 11.62$ & $48.50 \pm 12.78$ \\
\hline \multirow[t]{2}{*}{ III } & \multirow[t]{2}{*}{ Dreaming } & Dark conditions & $43.78 \pm 13.12$ & $46.85 \pm 10.57$ & $51.74 \pm 10.81$ & $48.04 \pm 12.60$ \\
\hline & & $\begin{array}{l}\text { Well-lit } \\
\text { conditions }\end{array}$ & $51.19 \pm 9.74$ & $51.22 \pm 13.20$ & $54.66 \pm 8.94$ & $52.97 \pm 8.90$ \\
\hline \multirow[t]{2}{*}{ V } & \multirow[t]{2}{*}{ Sleep duration } & Dark conditions & $41.92 \pm 7.99$ & $47.82 \pm 9.83$ & $28.45 \pm 7.54$ & $43.15 \pm 8.63$ \\
\hline & & $\begin{array}{l}\text { Well-lit } \\
\text { conditions }\end{array}$ & $40.04 \pm 13.33$ & $42.64 \pm 11.12$ & $30.28 \pm 8.79$ & $41.88 \pm 9.54$ \\
\hline
\end{tabular}

${ }^{*}$ Difference between dark conditions and well-lit conditions $p<0.1$.

\section{Fatigue and sleepiness}

Questions on 'subjective symptoms' related to fatigue and sleepiness covered five factors: instability, uneasiness, grogginess, lethargy and drowsiness. Table 2 shows the means and SDs by factor. Overall mean scores were higher for the dark condition than for the well-lit condition, indicating that nurses experienced more subjective symptoms in the dark conditions. The items that were statistically significant and higher for the dark conditions compared with well-lit conditions were drowsiness before work on the last day shift before a night shift $(2.71 \pm 1.19$ vs $1.73 \pm 1.00)$, and lethargy on the first day after the night shift $(1.96 \pm 0.87$ vs $1.32 \pm 0.48$; $\mathrm{p}<0.05)$. For grogginess, lethargy and drowsiness, the dark condition displayed a higher trend than the well-lit condition $(\mathrm{p}<0.1)$. On a night-shift day, no significant differences were found for any symptom.

\section{Self-assessment of sleep quality on waking}

Table 3 shows the self-assessment of the sleep quality. Sleep induction and maintenance showed a higher trend in the case of well-lit conditions on the last day shift before a night shift than for dark conditions (well-lit conditions, $52.13 \pm 9.94$ vs dark conditions, $46.33 \pm 7.84$; $\mathrm{p}<0.1)$. However, there were no significant differences in any items between the dark and well-lit conditions.

\section{Work performance on safety}

Table 4 lists the numbers of incident and accident reports. These were divided into accidents ( $3 \mathrm{~b}$ or higher) and incidents (3a or lower). The percentages of the number of reports for the whole hospital were compared with those during the day and night shifts, but no significant differences were found. Regarding ratio of the total number of reports for day versus night shift, there was no significant difference in the study ward between the different conditions. As compared with total number of reports for the study ward and other wards during the well-lit condition, the study ward had significantly more reports for the night shift than for the whole hospital, excluding the study ward $(p<0.05)$. Related to medical treatment problems there were no light intensity-related reports during the entire study period.

\section{DISCUSSION}

No significant differences were observed in symptoms during a night shift in the dark conditions. A previous study, however, pointed out the satisfaction with the lighting and ease of concentration at work, ${ }^{15}$ as well as brightness at work and glare in the work area caused by lighting fixtures. The difference in illumination from the background, and in the brightness entering the visual field might give effects to symptoms at work; further analysis (such as luminance analysis) will be required in the future to ascertain this.

Regarding feelings about sleep quality, no significant differences were found in any items between the dark and well-lit conditions. Our results did not clearly indicate whether a dark environment prevents disruption of the circadian rhythm in night-shift nurses. ${ }^{1-4}$ A recent intervention study ${ }^{16}$ reported a positive effect on sleep among nurses by adjusting light exposure using both a portable light box (for 40 min exposure to bright light before night 


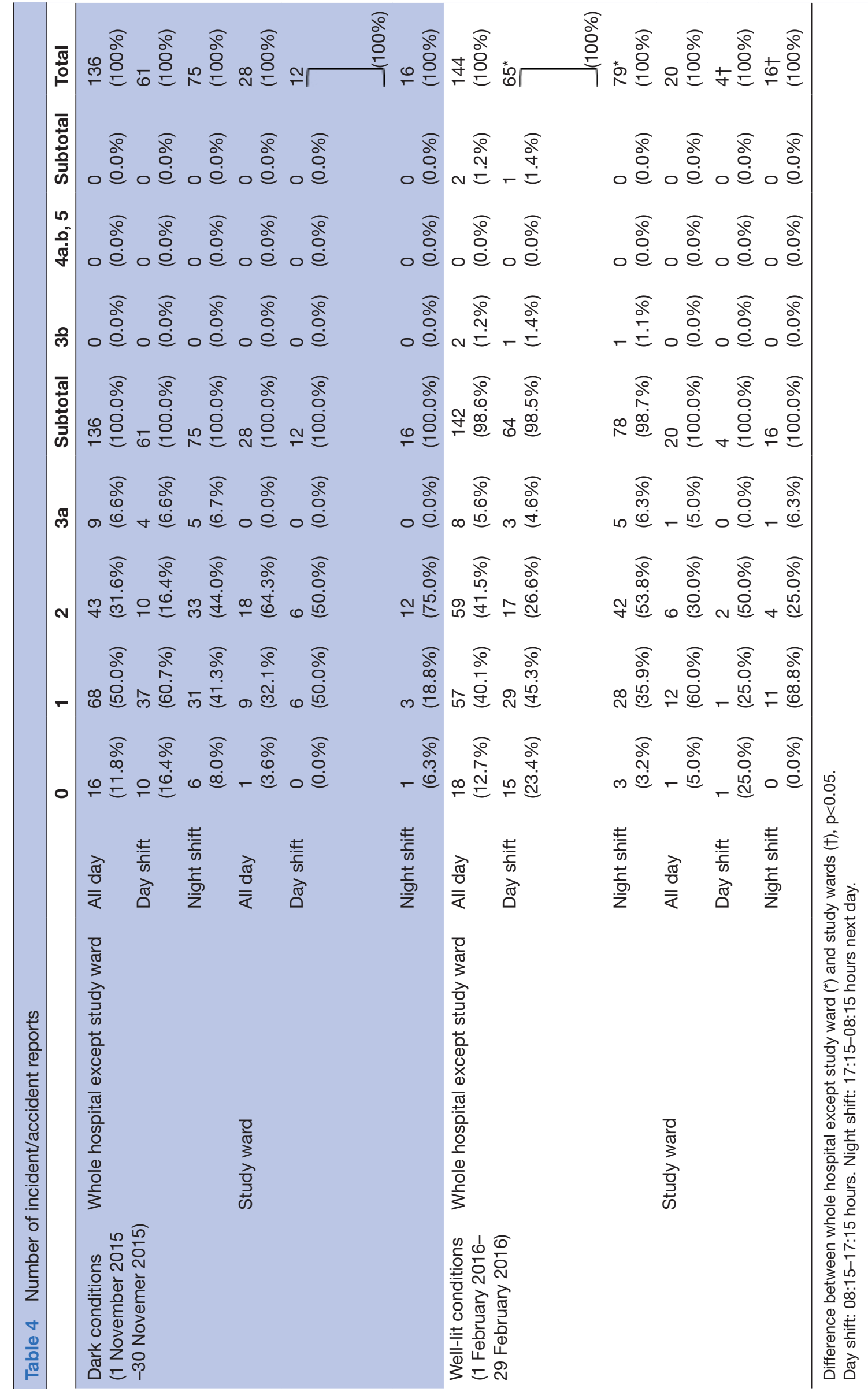


shift) and sunglasses (for avoiding bright light after the night shift). Environmental lighting improvement should be combined with individual-level, subtle adjustments to obtain a clearer effect. ${ }^{17}$

This study found that differences in lighting environment did not cause problems in work performance. The ratio of incidents during the day shift to those occurring during night shift was 3:4, while for the well-lit condition, the ratio was 1:4. The number of night-shift incidents was significantly larger in well-lit conditions. A previous study reported that a bright lighting environment for ICU nurses working at night shifts reduced sleepiness but increased the number of psychomotor errors. ${ }^{16}$ The study ward at the hospital was designed so that when the nurses' work space was bright, patient rooms would also be bright. At nighttime after 21:00 hours, however, the patient rooms become dark to help them sleep well. Therefore, bright light coming from a well-lit working station might have affected patients' sleeping conditions, causing a relatively high frequency of incidents like a slipping from the bed.

\section{Study limitation}

The available sample size was insufficient to detect any statistical significance. It could also be true that there was no significant effect of the dark condition during the night shift. There may have been confounding factors regarding fatigue and feeling sleepy (such as exposure to sunlight, exercise and alcohol consumption) for which information was not collected. Other missing information included the patients' medical conditions, new hospitalisation cases during the night shifts and the number of empty beds. Since this study was conducted at only one institution, we note that it may not be fully representative or generalisable. The results obtained from the present study merely suggest the importance of monitoring the lighting environment in hospitals and conducting further studies. Despite the major limitation of sample size, our trial suggests a way of evaluating the working environment in hospitals using a quasi-experimental design with minimal interference to routine work.

\section{CONCLUSION}

Caring for the health of night-shift workers to prevent rapid turnover of staff due to unfavourable work environments is important for hospital management as well as for patient safety. The objectives of this study were to investigate whether dark environments bring improvement in terms of (1) fatigue and sleepiness on working, (2) quality of sleep and (3) unhindered work performance (no malpractice/incidents/accidents) among nurses. Among these three variables, we could not find significant results for (1) and (2) partly due to the small sample size. However, we clarified that lighting did not interfere with work performance in a dark environment. Although, a further large-scale study with more rigorous data collection on lightning should be conducted, this study suggests that lower lighting levels on night shifts is acceptable for nurses' work environment and safety management in general wards of hospitals. To our knowledge, minimum lighting has not yet been used in hospitals. The study site continues to employ the dark condition, and a few other hospitals now follow this method, which may enable a multisite evaluation in the future.

Acknowledgements The authors would like to thank Dr Nobuaki Moriyama from the Department of Public Health, Fukushima Medical University School of Medicine, for his support in editing the manuscript.

Contributors $\mathrm{HH}$ conceived the study idea, collected the data and analysed data. $\mathrm{HI}, \mathrm{AG}$ and SY contributed to writing the article. $\mathrm{HH}$ acted as guarantor of this paper

Funding The authors have not declared a specific grant for this research from any funding agency in the public, commercial or not-for-profit sectors.

Competing interests None declared.

Patient and public involvement Patients and/or the public were not involved in the design, or conduct, or reporting, or dissemination plans of this research.

Patient consent for publication Not applicable.

Ethics approval This study involves human participants and was approved by Fukushima Medical University (no. 2546). Participants gave informed consent to participate in the study before taking part.

Provenance and peer review Not commissioned; externally peer reviewed.

Data availability statement No data are available.

Open access This is an open access article distributed in accordance with the Creative Commons Attribution Non Commercial (CC BY-NC 4.0) license, which permits others to distribute, remix, adapt, build upon this work non-commercially, and license their derivative works on different terms, provided the original work is properly cited, appropriate credit is given, any changes made indicated, and the use is non-commercial. See: http://creativecommons.org/licenses/by-nc/4.0/.

\section{REFERENCES}

1 Aoki H, Yamada N, Ozeki Y, et al. Minimum light intensity required to suppress nocturnal melatonin concentration in human saliva. Neurosci Lett 1998;252:91-4.

2 Hashimoto S, Nakamura K, Honma S, et al. Melatonin rhythm is not shifted by lights that suppress nocturnal melatonin in humans under entrainment. Am J Physiol 1996;270:R1073-7.

3 Mclntyre IM, Norman TR, Burrows GD, et al. Human melatonin suppression by light is intensity dependent. $J$ Pineal Res 1989;6:149-56.

4 Warman VL, Dijk DJ, Warman GR, et al. Phase advancing human circadian rhythms with short wavelength light. Neurosci Lett 2003;342:37-40.

5 Ohida T, Kamal AMM, Sone T, et al. Night-Shift work related problems in young female nurses in Japan. $J$ Occup Health 2001;43:150-6.

6 Takahashi M. Assisting shift workers through sleep and circadian research. Sleep Biol Rhythms 2014;12:85-95.

7 Tanaka K, Takahashi M, Tanaka M, et al. Brief morning exposure to bright light improves subjective symptoms and performance in nurses with rapidly rotating shifts. J Occup Health 2011;53:258-66.

8 Boivin DB, Boudreau P. Impacts of shift work on sleep and circadian rhythms. Pathol Biol 2014;62:292-301.

9 Watanabe T. Hyper light treatment for insomnia. Advances in Neurological Science 2001;45:817-25.

10 Schaefer EW, Williams MV, Zee PC. Sleep and circadian misalignment for the hospitalist: a review. J Hosp Med 2012;7:489-96.

11 Matsunaga N. Effects of bright light on nocturnal sleepiness. Electroencephalography and Electromyography 1997;25:260-8.

12 Sakai K. The Japanese Society for Occupational Health, Occupational Fatigue Study Group, Revision of "Subjective Disease Report" 2002. Science of Labor 2002;57:295-8.

13 Yamamoto $\mathrm{Y}$, Tanaka H, Takase M. Standardization of revised version of OSA (Oguri-Shirakawa-Azumi) sleep inventory for middle age and aged. Brain Science and Mental Disorders 1999;10:401-9. 
14 Griepentrog JE, Labiner HE, Gunn SR, et al. Bright environmental light improves the sleepiness of nightshift ICU nurses. Crit Care 2018;22:295.

15 Suzuki M, Iwamoto Y, Fujii K. Decreasing of eyestrain of nurses: by well-lit environment at night-shift in intensive care unit. In: Fukui Prefectural Hospital reports of nursing research, 2008: 30-5.
16 Olson JA, Artenie DZ, Cyr M, et al. Developing a light-based intervention to reduce fatigue and improve sleep in rapidly rotating shift workers. Chronobiol Int 2020;37:573-91.

17 Sun Q, Ji X, Zhou W, et al. Sleep problems in shift nurses: a brief review and recommendations at both individual and institutional levels. J Nurs Manag 2019;27:10-18. 